\title{
The Fluorescent 7-Aminodipyrido[3,2-a:2',3'-c] phenazine(7-amino-dppz) Functionalized as an Europium Ion $\left(\mathrm{Eu}^{3+}\right)$ Sensor
}

\author{
Chang-Shik Choi, ${ }^{*}$ and Ki-Hwan Lee ${ }^{\dagger}$ \\ Department of Oriental Medicine Resources, Far East University, Eumseong, Chungbuk 369-851, Korea \\ *E-mail: cschoi@kdu.ac.kr \\ † Department of Chemistry, Kongju National University, Kongju 314-701, Korea
}

\begin{abstract}
The Fluorescent 7-aminodipyrido[3,2-a:2',3'c]phenazine (7-amino-dppz, 1) is functionalized as an europium ion $\left(\mathrm{Eu}^{3+}\right)$ sensor, which showed the effective emission quenching when europium cation is chelated to the bpy site of 1 compound. The complexation ratio indicated that the 1 compound forms a $1: 1$ complex with $\mathrm{Eu}^{3+}$.
\end{abstract}

Fluorescent artificial receptors are attracting considerable interest in sensory, biochemical, medical, photoelectronic and other applications. ${ }^{1}$ These receptors are composed of a host unit (binding site) and a signaling unit (fluorescent site), and communication between the two units is essential for guest specific response. Though various molecular designs have been proposed in order to develop efficient fluorescent receptors, ${ }^{2}$ most receptors are designed by introducing molecular recognition site(s) into known fluorophores. However, this approach alone is not sufficient to develop novel fluorescent receptors with high sensitivity or other useful properties, since connection of the host unit often attenuates the emission property of the parent fluorophore. In addressing this point, new design strategy, rendering fluorescence properties to a nonfluorescent functional unit, should be developed.

Polypyridyl compounds are useful molecular units as binding sites. They have multiple interaction sites, and the number of pyridine units is adjustable. 2,2-Bipyridine (bpy) is the most studied among such compounds owing to its excellent property as a bidentate ligand and as a hydrogen bond acceptor. ${ }^{3}$ Moreover, rational receptor design using more than one bpy unit can lead to selective and strong interaction with guests. ${ }^{4}$ However,

*To whom correspondence should be addressed.

E-mail: cschoi@kdu.ac.kr

Received April 3. 2012. Accepted May 23. 2012 bpy itself is non-fluorescent, ${ }^{5}$ and only a limited number of fluorescent bpy based species have been known until now. ${ }^{6}$ We previously reported ${ }^{6 c}$ that 6 -amino substitution is an effective method to convert non-fluorescent bpy to a strongly fluorescent species, and have demonstrated that the resultant fluorescent bpy derivative served as a highly sensitive fluorescent receptor for phosphodiester guests. $^{3 b}$ The essence of the molecular design is that a known fluorescent dye, 2-aminophenazine $(2-a p h z),{ }^{7}$ is integrated with a non-fluorescent bpy. Therefore, as reported previously, ${ }^{8}$ the resultant 7 -aminodipyrido[3,2$a: 2,3-c]$ phenazine (7-amino-dppz, 1) was synthesized. The 1 compound and its derivatives were studied in order to examine the metal ion sensing ability through the spectroscopic method. These fluorescent materials have been almost utilized as a metal ion sensing study for monovalent or divalent metal cation. In this paper, the study on europium cation sensing ability of 1 compound is reported. In addition, the fluorescent site of 1 compound is investigated by using the $\mathrm{ZINDO}^{9}$ (CI = 9) method after successive geometrical optimizations by MM2 and MOPAC/AM1 ${ }^{10}$ calculations in order to observe the fluorescence behavior of 1 compound after chelation of europium ion. All spectroscopic measurements were carried out with $1.95 \times 10^{-5} \mathrm{~mol} \mathrm{dm}^{-3} 1$ compound in acetonitrile at room temperature. Thus the fluorescence titration experiment was carried out by adding up to europium ion 5 equivalent to $1.95 \times 10^{-5} \mathrm{~mol} \mathrm{dm}^{-3} 1$ compound in acetonitrile at room temperature. As shown in Fig. 1, the molecular orbitals and the simulated absorption spectra of 1 compound and 2-aphz were investigated by using ZINDO method. The results of this calculation clearly demonstrate that the HOMO and LUMO orbitals are localized on the phenazine site and these orbitals are involved in the lowest energy absorption band. 

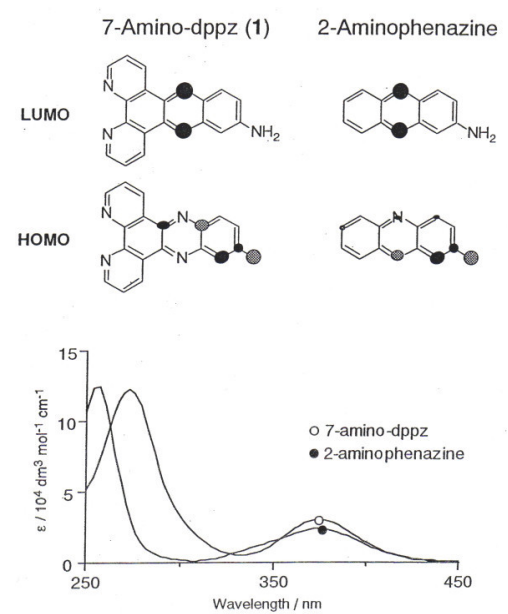

Figure 1. Calculated molecular orbitals and simulated absorption spectra of 1 compound and 2-aminophenazine by ZINDO

As shown in Fig. 2, the absorption peaks of 1 compound were found at $295 \mathrm{~nm}$ and $440 \mathrm{~nm}$ due to $\pi^{-} \pi *$ and $\mathrm{n}-\pi *$ transitions, respectively, along with the absorption shoulder at $350 \mathrm{~nm}$. The isosbestic points were observed at $320 \mathrm{~nm}$,

$390 \mathrm{~nm}$ and $450 \mathrm{~nm}$. The two absorption peaks of 1

compound were redshifted to $300 \mathrm{~nm}$ and $450 \mathrm{~nm}$, respectively, upon addition of europium ion in the presence of $1.95 \times 10^{-5} \mathrm{~mol} \mathrm{dm}^{-3} 1$ compound in acetonitrile at room temperature. Meanwhile, when 1 compound was excited at $365 \mathrm{~nm}$, the fluorescence emission peak appeared at 550 nm. As shown in Fig. 2, when europium ion was added up to 5 equivalent in the presence of $1.95 \times 10^{-5} \mathrm{~mol} \mathrm{dm}^{-3} 1$ compound in acetonitrile, the fluorescence emission peak was decreased and almost quenched at about 5equivalents. Also, as shown in the inset, this fluorescence behavior could be confirmed when the change of the fluorescence emission intensity was plotted as the complexation ratio related to $\left[\mathrm{Eu}^{3+}\right] /[1]$ at the emission wavelength $550 \mathrm{~nm}$.

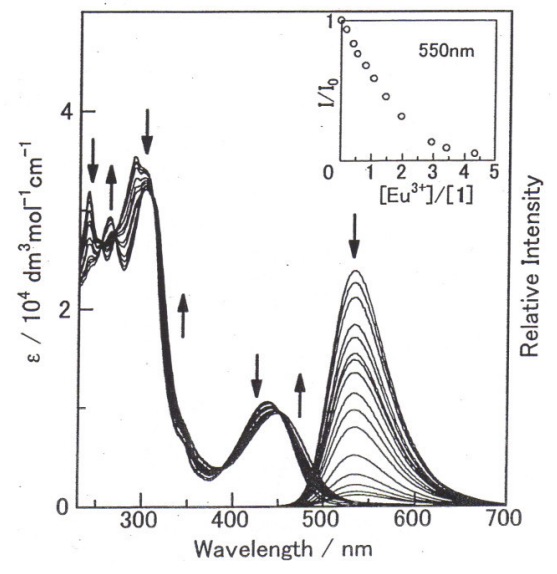

Figure 2. Absorption and fluorescence spectral titration of 1 compound $\left(1.95 \times 10^{-5} \mathrm{~mol} \mathrm{dm}^{-3}\right)$ upon addition of $\mathrm{Eu}^{3+}$ (up to 5 equivalents) in acetonitrile at room temperature.

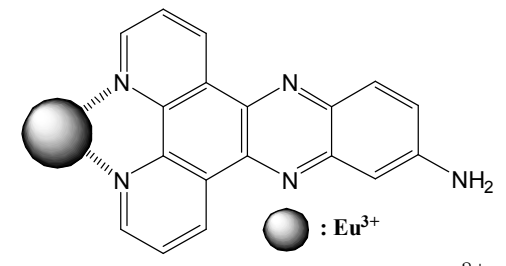

Figure 3. The complex structure of $\left[\mathrm{Eu}^{3+}\right]:[1]=1: 1$ appeared in 1 compound $\left(1.95 \times 10^{-5} \mathrm{~mol} \mathrm{dm}^{-3}\right)$.

Association constant $\left(\mathrm{M}^{1}\right)$ between 1 compound and europium ion was estimated to be $K_{\mathrm{a}}=2.9 \times 10^{4} \mathrm{M}^{1}$ by computational simulation. This association constant was almost consistent with the association constant (very smaller than $K_{\mathrm{a}}=1 \times 10^{10} \mathrm{M}^{1}$ ) obtained in the complexation ratio $\left[\mathrm{M}^{2+}\right]:[1]=1: 1$.

We was known from this result that this complex structure is $\left[\mathrm{Eu}^{3+}\right]:[1]=1: 1$, not $\left[\mathrm{Eu}^{3+}\right]:[1]=1: 2$ due to having the value more than $K_{\mathrm{a}}=1 \times 10^{10} \mathrm{M}^{1}$ in the case of complexation ratio $\left[\mathrm{M}^{2+}\right]:[1]=1: 2$ as reported previously. ${ }^{8}$

In conclusion, we confirmed that the electronic communication between bpy chelating unit and fluorescent phenazine unit is existed and the europium chelating to 1 compound is induced to effective emission quenching occurred from phenazine unit. In particular, this results will be opened a new way for the application as an effective metal ion sensor in the near future.

KEYWORDS: europium ion sensor, absorption, fluorescence, complexation, fluorescence titration, phenazine

\section{ACKNOWLEDGEMENT}

This work was supported by the National Research Foundation of Korea (NRF) grant funded by the Korea Government (MEST) (No. 2012-0004677) and Far East University.

\section{REFERENCES AND NOTES}

1. (a) Fluorescent and Luminescent Probes for Biological Activity, ed. Mason, W. T., Academic Press, San Diego, 2nd edn., 1999; (b) Introduction to the Issue on Organic Electroluminescence, ed. Forrest, S. R. and Burrows, P. E., IEEE, New York, 1998; (c) Fluorescence Spectroscopy: New Method and Application, ed. Wolfbeis, O. S., Springer-Verlag, Berlin, 1993; (d) Soper, S. A., Warner, I. M. and McGown, L. B., Anal. Chem., 1998, 70, 477R.

2. (a) de Silva, A. P., Gunaratne, H. Q. N., Gunnlaugsson, T., Huxley, A. J. M. McCoy, C. P., Rademacher, J. T. and Rice, T. E., Chem. Rev., 1997, 97, 1515; (b) Araki, Tada, K., Abe, K., M. and Mutai, T., J. Chem. Soc., Perkin Trans. 2, 1998, 1391.

3. (a) Balzani, V., Juris, A., Venturi, M., Campagna, S. and Serroni, S., Chem. Rev., 1996, 96, 759; (b) Mutai, T., Abe, Y. and Araki, K., J. Chem. Soc., Perkin Trans. 2, 1997, 1805. 
4. (a) Sohna, J.-E. S., Jaumier, P. and Fages, F., J. Chem. Res. (S), 1999, 134; (b) Chin, T., Gao, Z., Lelouche, I., Shin, Y.-G. K., Purandare, A., Knapp, S. and Isied, S. S., J. Am. Chem. Soc., 1997, 119, 12849.

5. Summers, L. A., Adv. Heterocycl. Chem., 1984, 35, 281.

6. (a) Bulska, H., Chem. Phys. Lett., 1983, 98, 398; (b) Sepiol, J., Bulska, H. and Grabowska, A., Chem. Phys. Lett., 1987, 140, 607; (c) Araki, K., Mutai, T., Shigemitsu, Y., Yamada, M., Nakajima, T., Kuroda, S. and Shimao, I., J. Chem. Soc., Perkin Trans. 2, 1996, 613.

7. Ya. Dain, B., Eremenko, S. M. and . Kalibabchuk, V. A, Teor. Eksp. Khim., 1972, 8, 49.

8. Choi, C.-S, Mutai, T., Arita, S. and Araki, K., J. Chem. Soc., Perkin Trans. 2, 2000, 243.

9. (a) Pople, J. A., Beveridge, D. L. and Dobosh, P. A., J. Chem. Phys., 1967, 47, 2026; (b) Ridley, J. and Zerner, M. C., Theor. Chim. Acta, 1973, 32, 111; (c) Anderson, W. P., Cundarai, T. R., Drago, R. S. and Zerner, M. C., Inorg. Chem., 1990, 29, 1.

10. Dewar, M. J. S., Zoebisch, E. G., Healy, E. F. and Stewart, J. J. P., J. Am. Chem. Soc., 1985, 107, 3902. 